\title{
26 Research Square \\ Selected Micro RNAs Regulate Drug Resistance Genes in Breast Cancer.
}

\section{Shumaila Zaib}

Fatima Jinnah Women University

Azra Yasmin

Fatima Jinnah Women University

Nosheen Masood ( $\nabla$ dr.nosheen@fjwu.edu.pk)

Fatima Jinnah Women University https://orcid.org/0000-0001-8909-6587

\section{Research Article}

Keywords: MicroRNAs, breast cancer, genetic polymorphism, progression free survival

Posted Date: June 14th, 2021

DOI: https://doi.org/10.21203/rs.3.rs-580368/v1

License: (1) This work is licensed under a Creative Commons Attribution 4.0 International License.

Read Full License 


\section{Abstract}

Background: Breast cancer initiation is an unresolved phenomenon although many genes are known to be involved in its initiation but its exact etiology is still unexplained in many aspects and recently microRNAs are found to regulate many genes expressions.

Method: This case control study has been designed to evaluate the role of selected miRNAs in gene expression and subsequent association with drug resistance. Genetic polymorphisms were confirmed by PCR-SSCP followed by sequencing and microRNA expression was measured by realtime PCR with specific primers. Follow up was done for patients whose samples were used in the study.

Results: This study revealed 15 germline mutations in mdr1, 5 in ABCG2, 8 in BRCA1 and 8 in PTEN gene. These mutations were significantly associated with breast cancer compared with control tissues $(P<0.05)$. miR-21, miR-146a and miR-328 were over expressed whereas miR-451 was under expressed. Progression free survival (PFS) was linked with reduced polymorphisms in genes as well as microRNAs.

Conclusion: Over expression of miRNA-21 and miRNA-146a may lead towards lower expression of PTEN and BRCA1 genes causing cancer progression. miRNA-328 and miRNA-451 reduced expression resulted in overexpressed ABCG2 and MDR1 genes in this study.

\section{Introduction}

Breast cancer is the most common malignancy in Pakistani females, whereas it is the second most common cancer in female in other Asian countries. However it is the rare disease found in men and contributes less than $1 \%$ of total cancers in males [1]. Many genes have been identified that are associated with breast cancer. In process of tumor initiation and progression, major role is played by mutations, and abnormal amplification of both oncogenes and anti-oncogenes. BRCA1 and BRCA2 are two well-known anti-oncogenes for breast cancer risk [2, 3]. Various mutations in different BRCA1 exons have been reported in literature. Four most frequent BRCA1 mutations $(2798 \mathrm{~T}>\mathrm{C}, 3971 \mathrm{G}>\mathrm{A}, 4921 \mathrm{G}>\mathrm{A}$ and $624 \mathrm{C}>\mathrm{T}$ ) in exon 10 have been found by Sun et al., [4]. Likewise, several mutations in exon 11 were found by Farooq et al. [5] in BRAC1. About 5 BRAC1 mutations were found by Rasheed et al. [6, 7] which were unique to Pakistani population. In Pakistani people mutations were reported mainly in exon 2, exon $6(271 \mathrm{~T}>\mathrm{G})$, exon $11(1123 \mathrm{~T}>\mathrm{G})$ and exon 20 (5231 delG). Chen et al. (2007) conducted meta analysis and found that risk ratio of $\mathrm{Ca}$ breast in women above 70 having mutations in BRAC2 and BRAC1 was $49 \%$ and $57 \%$ respectively [8]. An important tumor suppressor gene is phosphatase and tensin homolog (PTEN) and its functions are cell growth regulation, proliferation, regulation of cell cycle and apoptosis in signal transduction pathways [4]. Many mutations were identified in PTEN gene and $42 \%$ were in exon 9 and 4 [9]. Kechagioglou et al., amplified PTEN exons and found 21 mutations in exon 9, 7 and 1 while in exon 5 about 34 mutations were found and all were single based alterations [10]. One of the best processes responsible for the multi-drug resistant phenotype in breast cancer patients is the enhanced ability of cancer cells to transport drugs out of the cell, by the use of one or more ATP-dependent 
transporters[11]. In human multidrug resistant genes, more than 50 single nucleotide polymorphisms have been observed. Among them, C3435T single nucleotide polymorphism on exon 26 as a silent mutation, found to affect the expression level of MDR1 and consequently drug resistance of cells [12]. Another important member of the ATP-binding cassette (ABC) transporters is ABCG2. The carriers of the A allele of ABCG2 C421A had an increased risk of cancer. Three SNP (34 G > A, 421 C > A and $1143 \mathrm{C}>\mathrm{T}$ ) were reported by Tandia et al. [13].

MicroRNAs (miRNAs) are small RNA molecules of nearly 20-25 nucleotides long. They are noncoding RNAs but they are posttranscriptional regulators of gene expression. Studies revealed that they are present intergenic but in some cases they may be in the intronic or exonic regions [14]. In case of humans more than 200 mRNAs have been shown to be involved in cancer progression. Cancer is caused due to alterations in either tumor suppressor or oncogenes and miRNAs are involved in cancers of lung cancer, gastric carcinoma, colon cancer etc. Alterations in miRNA expression have also been found in premalignant stages of cancer [15]. miRNAs may act as tumor suppressor genes when they are downregulated and oncogenes when they are over expressed. Interaction of miR-146a with 3' UTRs of BRCA1 is involved in regulation of their expression. Upregulation of miR-146a leads to altered expression of BRCA1. Yao et al., [16] reported the involvement of micro RNA-146a in many different types of cancer including breast cancer, so by correctly targeting micro RNA-146a, the proper functioning of its target genes can be restored [17]. Micro RNA-21 is one of the most frequently aberrant micro RNAs in human cancer $[18,19]$. Among molecules down regulated by micro RNA-21, most important is PTEN. Upregulated miR-21 downregulates PTEN therefore leads to cancer progression. Interaction of miR-146a with 3' UTRs of BRCA1 is involved in regulation of their expression. Upregulation of miR-146a leads to altered expression of BRCA1. The level of miR-451 is inversely related to mdr1, similarly miR-328 negatively regulates $A B C G 2$ activity. Both of these genes function to reduce the intracellular concentration of a wide spectrum of drugs and antibiotics [20]. But their over expression causes drug resistance of cancer cells to drugs given for breast cancer therapy. Therefore their expression must be regulated by targeting their regulatory miR.

This particular study is going to be focused on mutations in the selected genes (BRCA1, PTEN, ABCG2 and MDR1) and alteration in expression of these genes by selected micro RNAs and subsequently survival analysis and disease free progression will also be studied.

\section{Methodology}

Fresh $2 \mathrm{~cm}^{3}$ cancerous and control tissue samples of breast cancer patients were collected in RNA later. Total sample size was 25 cancerous and 25 non-cancerous tissues and subsequently their consent forms were filled by individuals or their attendants. All samples were collected over a period of six months from Pakistan Institute of Medical Sciences, Islamabad. All samples were stored at $-80^{\circ} \mathrm{C}$ till further use. From tissues, DNA and RNA was extracted by organic method by using TRIzol® LS reagent (Cat\# 10296-028). Extraction was done by following manufacturer's protocol (Invitrogen). 
PCR technique was used to amplify the sequence of different exons of BRCA1, PTEN, MDR1 and ABCG2 genes. Temperature profile of PCR reaction for the specific gene primers (Table 1) was initial denaturation of reaction mixture was done at $94^{\circ} \mathrm{C}$ for 1 minute in a single cycle, followed by 35 cycles of 3 step PCR: denaturation at $94^{\circ} \mathrm{C}$ for 45 seconds, annealing temperature for 45 seconds, extension at $72^{\circ} \mathrm{C}$ for 45 seconds and final extension of PCR product was carried out for 10 minutes at $72^{\circ} \mathrm{C}$ and then stored at $-20^{\circ} \mathrm{C}$ until further processing. Protocol followed for single stranded conformational polymorphism was adopted from Masood et al., [21]. For sequencing, 50ul of PCR product was send to Macrogen (Korea) for purification and sequencing. Bioedit software was used to read the sequences and for further mutational analysis.

\section{Table 1}

PCR reaction mixture using BRCA1, PTEN, MDR1 and ABCG2 gene primers

\begin{tabular}{|l|l|}
\hline Components & Volume \\
\hline Nuclease free water & $30 \mu \mathrm{L}$ \\
\hline $10 X$ buffer & $5.0 \mu \mathrm{L}$ \\
\hline $25 \mathrm{mM} \mathrm{MgCl}_{2}$ & $3.0 \mu \mathrm{L}$ \\
\hline $2.5 \mathrm{mM}$ dNTPs & $4.0 \mu \mathrm{L}$ \\
\hline Taq & $1.0 \mu \mathrm{L}$ \\
\hline Forward primer & $1.0 \mu \mathrm{L}$ \\
\hline Reverse primer & $1.0 \mu \mathrm{L}$ \\
\hline DNA sample & $5.0 \mu \mathrm{L}$ \\
\hline Total volume & $50 \mu \mathrm{L}$ \\
\hline
\end{tabular}

miRNA ANALYSIS

All-in-OneTM miRNA qRT-PCR Detection Kit for quantitative detection of mature miRNA (geneocopia Cat. No. QP015) was used according to the manufacturer protocol. The resulting reverse transcription reaction product was diluted $5 \sim 50$ times with sterile $\mathrm{H} 2 \mathrm{O}$ before using for the next qPCR experiment or it was directly stored at $-20^{\circ} \mathrm{C}$. For detection of miRNA using qPCR 2xAll-in-OneTM qPCR mix was mixed by gently inverting. Briefly centrifuged and placed the tubes on ice. The $50 \mu \mathrm{M}$ Universal Adaptor PCR Primer was diluted to $2 \mu \mathrm{M}$ with sterile ddH2O before using for the next qPCR experiment. qPCR solution was prepared on ice. For $20 \mu \mathrm{l}$ reaction $10 \mu \mathrm{l}$ of $2 \times A$ All-in-One qPCR Mix along with $2 \mu \mathrm{l}$ of All-in-OneTM miRNA qPCR Primer $(2 \mu \mathrm{M}), 2 \mu$ of Universal Adaptor PCR Primer, $2 \mu \mathrm{l}$ of First-strand cDNA (diluted 1:5) and $4 \mu \mathrm{l}$ water (double distilled). The qPCR reaction solution was thoroughly mixed and added to PCR tubes, and 
briefly centrifuged to make sure that all the reagents are in the bottom of the tubes. Following standard 3step method for the qPCR reaction was used; initial denaturation at $95^{\circ} \mathrm{C}$ for $10 \mathrm{~min}$ than 40 cycles of denaturation at $95^{\circ} \mathrm{C}$ for $10 \mathrm{sec}$, annealing at $58^{\circ} \mathrm{C}$ for $20 \mathrm{sec}$, extension at $72^{\circ} \mathrm{C}$ for $10 \mathrm{sec}$ and detection was measured at this stage. Melting curve was obtained at $65^{\circ} \mathrm{C} \sim 95^{\circ} \mathrm{C} 0.5^{\circ} \mathrm{C} /$ time $6 \mathrm{sec} /$ time. Control, positive and negative controls were also added with reaction.

Excel and graphpad prism was used for statistical evaluation of results related to different demographic factors. Significance level was below 0.05 . Chi square test and $T$ test were used for finding the association of factors with breast cancer.

\section{Results}

\subsection{Status of genetic mutations in breast cancer patients}

The results of sequencing revealed that in mdr1 gene following mutations were found; 1) g.1048delA, 2) g.1054delA, 3) g.1048delA, 4) g.1054delA, 5) g.1565A > T, 6) g.1571A > T 7) g. 1567delC, 8) g.3435C > T (rs1045642), 9) g.3664addA, 10) g.167673delC 11) g.16765delA, 12) g.1236C > T (rs1128503), 13) g.2677G > T (rs2032582), 14) g.87553926G > A and 15) g.185498G > A.

In ABCG2 gene following mutations were observed; 1) g.88113522addC, 2) g.88113525addT, 3) g.34G > A 4) g.88136922addG and 5) g.421C >A. In BRCA1, g.126382A > T, g.126383C > A, g.266delT, g.336insA, g.719insA, g.1443C > T, g.1563C > G and g.1755insC were found. In PTEN, g.263010delA, g.26353addC, g.87969686G > C, g. $87945672 \mathrm{C}>\mathrm{G}, \mathrm{g} .87961655 \mathrm{C}>\mathrm{T}, \mathrm{g} .87963585 \mathrm{C}>\mathrm{T}$, g.87966988T $>\mathrm{C}$ and g. $87972113 \mathrm{~A}>\mathrm{G}$ mutations were found. The patients with 4th stage of breast cancer have most of the mutations in tissues $(P<0.05)$. It was found that late stages of cancer and older aged patients had more mutated DNA compared with young and early staged patients.

Figure 1 and 2 shows representative pictures of agarose gel electrophoresis after PCR and results of sequencing respectively.

\subsection{MicroRNA expression of miR-21 using realtime PCR}

It was found that miRNA-21 was overexpressed in three tumor tissues compared with control tissues $(\mathrm{P}<$ 0.05) (Fig. 3). It was found that one of the patients having microRNA-21 variation also had mutation in $A B C G 2$ gene and is alive and healthy, another patient ABCG2 as well as BRCA1 gene mutation and upon follow-up it was found that she had died as her cancer was metastasized. This means that variation in miRNA-21 lead towards cancer progression via effecting PTEN along with mutation in ABCG2 gene lead towards drug resistance as well as. The third patient that showed variation in miRNA-21 had mutated PTEN as well and she is currently suffering from lung cancer that revealed the association of the miRNA with gene leading towards cancer progression. Therefore it showed that the overexpression of this microRNA leads to low expression of PTEN and enhanced cancer progression gene resulting in cancer recurrence. 


\subsection{MicroRNA expression of miR-146a using realtime PCR}

miRNA-146a was found to be overexpressed in two patients compared with control tissues $(P<0.05)$ (Table 1 and Fig. 4). It was found that these patients were living a healthy life with no cancer recurrence. One of the patient had ABCG2 mutation as well in the tumor tissue but blood DNA showed no mutation in the germline. Therefore these patients were not drug resistant and the chances of cancer progression and recurrence were also low based on these genes and miRNA analysis.

\subsection{MicroRNA expression of miR-328 using realtime PCR}

Three patients showed overexpression of miRNA-328 (Table 1 and Fig. 5). It was optimized at $59^{\circ} \mathrm{C}$ and all the samples were run in realtime PCR at one time using different temperatures in each column of machine. It was found that one patient had no mutations in any gene and she was living healthy life however another patient had PTEN mutation and had lung cancer after breast cancer. Similarly third patient had ABCG2 mutation but living healthy life. This showed that one patient having miRNA-328 as well as ABCG2 mutation was healthy because the altered expression of miRNA didn't effected the gene expression.

\subsection{MicroRNA expression of miR-451 using realtime PCR}

miRNA-451 was found to be under expressed in 5 patients compared with controls $(P<0.05)$ (Table 1 and Fig. 6). Three patients had recurrent cancer one of them had BRCA1 and other had PTEN mutations as well but third had no mutations in tumor DNA. Two patients had died due to breast cancer metastasis they also had mutations in BRCA1, ABCG2 and mdr1 genes. This showed that the drug resistance genes were not functioning properly and the cancer prognostic and progression free genes were also abnormal. These factors may contributed towards disease spread and ultimately leading towards cancer metastasis. Another factor may be due the 4th stage of cancer identification. The details of microRNA analysis results are depicted in table 2 .

\subsection{Progression free survival analysis}

Overall it was found that $50 \%$ patients had progression free survival (PFS). PFS was found to be associated with less number of variations in genes and microRNAs $(P<0.05)$ (Fig. 7). It was found that these patients were identified and treated at early stages of cancer and had less mutations in these four genes and microRNAs.

In conclusion it was found that most of the patients of later stages of breast cancer had their tumor metastasized and were found in bad health conditions upon followups. Different mutations were found in mdr1, ABCG2, BRCA1 and PTEN genes were associated with breast cancer some of these were novel however few were already reported in literature. Old aged patients had more mutations compared with young patients. It was found that miRNA-21 and miRNA-146a was overexpressed, whereas miRNA 328 and miRNA-451 were under expressed in tumor tissues compared with surrounding normal tissues. Over expression of miRNA-21 and miRNA-146a leads towards lower expression of PTEN and BRCA1 genes 
causing cancer progression. miRNA-328 and miRNA-451 reduced expression resulted in overexpressed ABCG2 and mdr1 genes. Lower expression of these genes is known to cause drug resistance.

\section{Discussion}

Incidence of breast cancer has increased in the past few decades. Worldwide there are cases of breast cancer each year, whereas in Pakistan one in every five patients are of breast cancer (Pakistan Medical Research Counsel). Pakistani women show an incidence rate of 50 per 100,000 whereas in India it is 19 per 100,000 [7]. Exact etiology and reason for initiation of cancer is still unclear. Although breast cancer is a polygenic disease but recently few genes have been revealed that can be related as the prognostic marker of breast cancer and may also provide drug resistance [22]. miRNAs are involved in cell proliferation and also have antiapoptotic effects. PI3K/AKT is one of the pathway that mediate cell proliferation and apoptosis [23]. Upregulated miR-21 downregulates PTEN therefore leads to cancer progression. As single miRNA have ability to interact with multiple mRNA similarly miR-21 is also involved in targeting various genes other than PTEN like PDCD4, Bcl2, SEPINB5, TPM1, NCAPG, OXSR1 and SEC23A [24]. miR-21 can be used as a biomarker for the identification of cancer as it is found to deregulate many genes leading to development of breast cancer. It acts as an oncogene and is upregulated in all pathways in breast cancer. Therefore, by targeting miR-21, correct expression of many genes crucial to various pathways can be restored and it can serve as potential target for developing biomarker for diagnosis of breast cancer. Breast cancer type 1 suseptibility protein (BRCA1) has been found to be negative regulator of growth and is associated with hypophosphorylated form of Rb. Interaction of miR-146a with 3' UTRs of BRCA1 is involved in regulation of their expression. It has been found that sequential variations like presence of $\mathrm{C}: U$ pair instead of $\mathrm{G}: \mathrm{U}$ in precursor miR-146a molecule increase its affinity with which it binds to 3'UTR [25]. Upregulation of miR-146a leads to altered expression of BRCA1. miR-146a can also be used as a biomarker for breast cancer identification since it is deregulated in various pathways leading to the development of breast cancer [15]. It acts as a tumor suppressor gene. Thus, by correctly targeting miR146a, the proper functioning of its target genes can be restored. The role of miRNA as a prognostic and diagnostic indicator for human breast cancer is well established but their role in causing cancer drug resistance is still in the process of exploration. These molecules are also intercalated with breast cancer with the acquisition of drug resistance. The level of miR-451 is inversely related to mdr1. In breast cancer, there is downregulation of miR-451, leading to an increase in mdr1 levels. The product of mdr1 functions as an ATP-dependent efflux transporter, whose function is to protect body from environmental toxins. It functions to reduce the intracellular concentration of a wide spectrum of drugs and antibiotics [26]. When it is overexpressed in breast cancer, it causes drug resistance of cancer cells to drugs given for breast cancer therapy. Thus, miR-451 functions as an important regulator of mdr1 and to prevent drug resistance by mdr1. Another miRNA found in association with drug resistance is miR-328. It targets the ABCG2 and negatively regulates its activity. Downregulation of miR-328 has been observed in breast cancer, which leads to an upregulation of ABCG2. ABCG2 is an ATP binding cassette membrane transporter and is associated in the control of absorption, distribution and clearance of numerous xenobiotics, including pharmaceutical agents, dietary 
carcinogens and conjugated metabolites. An overexpression of ABCG2 has been found in drug resistant breast cancer tumor cells. Therefore, miR-328 dysregulation plays an important role in causing multidrug resistance [27].

\section{Declarations \\ Declarations}

\section{Conflict of interest}

All authors declare that there are no conflict of interests.

\section{Funding}

Authors would like to acknowledge Higher Education Commission of Pakistan for funding this research NRPU/4889.

\section{Author contribution}

Shumaila Zaib: Experimental work

\section{References}

1. Manai M, Abdeljaoued S, Goucha A, Adouni O, Bettaieb I, Bouzaien H, Rahal K, Birnbaum D, Bertucci F, Gamoudi A (2019) MARCKS protein overexpression is associated with poor prognosis in male breast cancer. Cancer Biomarkers (Preprint):1-10

2. Reagan M (2019) CAUSES OF CANCER: GENETIC, EPIGENETIC, VIRAL, MICROENVIRONMENTAL, AND ENVIRONMENTAL CONTRIBUTIONS TO CANCER. Prevention, Early Detection, Cancer, Treatment and Recovery:53-74

3. Paul P, Malakar AK, Chakraborty S (2019) The significance of gene mutations across eight major cancer types. Mutation Research/Reviews in Mutation Research

4. Sun L, Liu J, Wang S, Chen Y, Li Z (2014) Prevalence of BRCA1 gene mutation in breast cancer patients in Guangxi, China. Int J Clin Exp Pathol 7(9):6262

5. Farooq A, Naveed AK, Azeem Z, Ahmad T (2011) Breast and ovarian cancer risk due to prevalence of BRCA1 and BRCA2 variants in Pakistani population: a Pakistani database report. Journal of oncology 2011

6. Rashid MU, Muhammad N, Faisal S, Amin A, Hamann U (2013) Constitutional CHEK2 mutations are infrequent in early-onset and familial breast/ovarian cancer patients from Pakistan. BMC Cancer 13(1):312 
7. Rashid MU, Muhammad N, Naeemi H, Khan FA, Hassan M, Faisal S, Gull S, Amin A, Loya A, Hamann U (2019) Spectrum and prevalence of BRCA1/2 germline mutations in Pakistani breast cancer patients: results from a large comprehensive study. Hereditary cancer in clinical practice 17(1):27

8. Chen S, Parmigiani G (2007) Meta-analysis of BRCA1 and BRCA2 penetrance. Journal of clinical oncology: official journal of the American Society of Clinical Oncology 25(11):1329

9. Chai C, Wu H, Wang B, Eisenstat DD, Leng RP (2018) MicroRNA-498 promotes proliferation and migration by targeting the tumor suppressor PTEN in breast cancer cells. Carcinogenesis 39(9):1185-1196

10. Kechagioglou P, Papi RM, Provatopoulou X, Kalogera E, Papadimitriou E, Grigoropoulos P, Nonni A, Zografos G, Kyriakidis DA, Gounaris A (2014) Tumor suppressor PTEN in breast cancer: heterozygosity, mutations and protein expression. Anticancer research 34(3):1387-1400

11. Wang J, Gan C, Sparidans RW, Wagenaar E, van Hoppe S, Beijnen JH, Schinkel AH (2018) Pglycoprotein (MDR1/ABCB1) and breast cancer resistance protein (BCRP/ABCG2) affect brain accumulation and intestinal disposition of encorafenib in mice. Pharmacological research 129:414423

12. Yi D, Xu L, Wang R, Lu X, Sang J (2019) miR-381 overcomes cisplatin resistance in breast cancer by targeting MDR1. Cell Biol Int 43(1):12-21

13. Tandia M, Mhiri A, Paule B, Saffroy R, Cailliez V, Noé G, Farinotti R, Bonhomme-Faivre L (2017) Correlation between clinical response to sorafenib in hepatocellular carcinoma treatment and polymorphisms of P-glycoprotein (ABCB1) and of breast cancer resistance protein (ABCG2): monocentric study. Cancer Chemother Pharmacol 79(4):759-766

14. Mansoori B, Mohammadi A, Ghasabi M, Shirjang S, Dehghan R, Montazeri V, Holmskov U, Kazemi T, Duijf P, Gjerstorff M (2019) miR-142-3p as tumor suppressor miRNA in the regulation of tumorigenicity, invasion and migration of human breast cancer by targeting Bach-1 expression. Journal of cellular physiology 234(6):9816-9825

15. Faryal R (2011) Role of miRNAs in breast cancer. Asian Pac J Cancer Prev 12:3175-3180

16. Yao Q, Tu C, Lu D, Zou Y, Liu H, Zhang S (2017) Clinicopathological significance of the micro RNA146a/WASP-family verprolin-homologous protein-2 axis in gastric cancer. Cancer Sci 108(7):12851292

17. Yang Z, Liu Z (2020) The emerging role of microRNAs in breast cancer. Journal of Oncology 2020

18. Yao M, Lv X, Deng Y, Rasheed M (2019) Specific and simultaneous detection of micro RNA 21 and let-7a by rolling circle amplification combined with lateral flow strip. Analytica chimica acta 1055:115-125

19. Said E, Zidan A, Nawar A, Alhusseini N, Soliman E, Shaker R, Naguib W, Rady K, Baiumy H (2017) Circulating Micro RNA-21 and-92a as Biomarkers of Colorectal Cancer. Afro-Egyptian Journal of Infectious Endemic Diseases 7(4):247-257

20. Gotanda K, Hirota T, Saito J, Fukae M, Egashira Y, Izumi N, Deguchi M, Kimura M, Matsuki S, Irie S (2016) Circulating intestine-derived exosomal miR-328 in plasma, a possible biomarker for 
estimating BCRP function in the human intestines. Scientific reports 6:32299

21. Masood N, Kayani MA, Malik FA, Mahjabeen I, Baig RM, Faryal R (2011) Genetic variation in carcinogen metabolizing genes associated with oral cancer in Pakistani population. Asian Pac $\mathrm{J}$ Cancer Prev 12(2):491-495

22. Hou J, Wu J, Dombkowski A, Zhang K, Holowatyj A, Boerner JL, Yang Z-Q (2012) Genomic amplification and a role in drug-resistance for the KDM5A histone demethylase in breast cancer. American journal of translational research 4(3):247

23. Park K-R, Nam D, Yun H-M, Lee S-G, Jang H-J, Sethi G, Cho SK, Ahn KS (2011) $\beta$-Caryophyllene oxide inhibits growth and induces apoptosis through the suppression of PI3K/AKT/mTOR/S6K1 pathways and ROS-mediated MAPKs activation. Cancer letters 312(2):178-188

24. Xu L-f, Wu Z-p, Chen Y, Zhu Q-s, Hamidi S, Navab R (2014) MicroRNA-21 (miR-21) regulates cellular proliferation, invasion, migration, and apoptosis by targeting PTEN, RECK and Bcl-2 in lung squamous carcinoma, Gejiu City, China. PloS one 9 (8)

25. Labbaye C, Spinello I, Quaranta MT, Pelosi E, Pasquini L, Petrucci E, Biffoni M, Nuzzolo ER, Billi M, Foà R (2008) A three-step pathway comprising PLZF/miR-146a/CXCR4 controls megakaryopoiesis. Nat Cell Biol 10(7):788-801

26. Hoffmann U, Kroemer HK (2004) The ABC transporters MDR1 and MRP2: multiple functions in disposition of xenobiotics and drug resistance. Drug metabolism reviews 36(3-4):669-701

27. Li 1ABCDEFW-Q, Li2ABCDEFG Y-M, Tao2BCD B-B, Lu2ABCDEF Y-C, Hu2CDF G-H, Liu1DF H-M, He1CD J, Xu1CD Y, Yu1ABCDEFG H-Y (2010) Downregulation of ABCG2 expression in glioblastoma cancer stem cells with miRNA-328 may decrease their chemoresistance. Med Sci Monit 16 (10):30

\section{Figures}



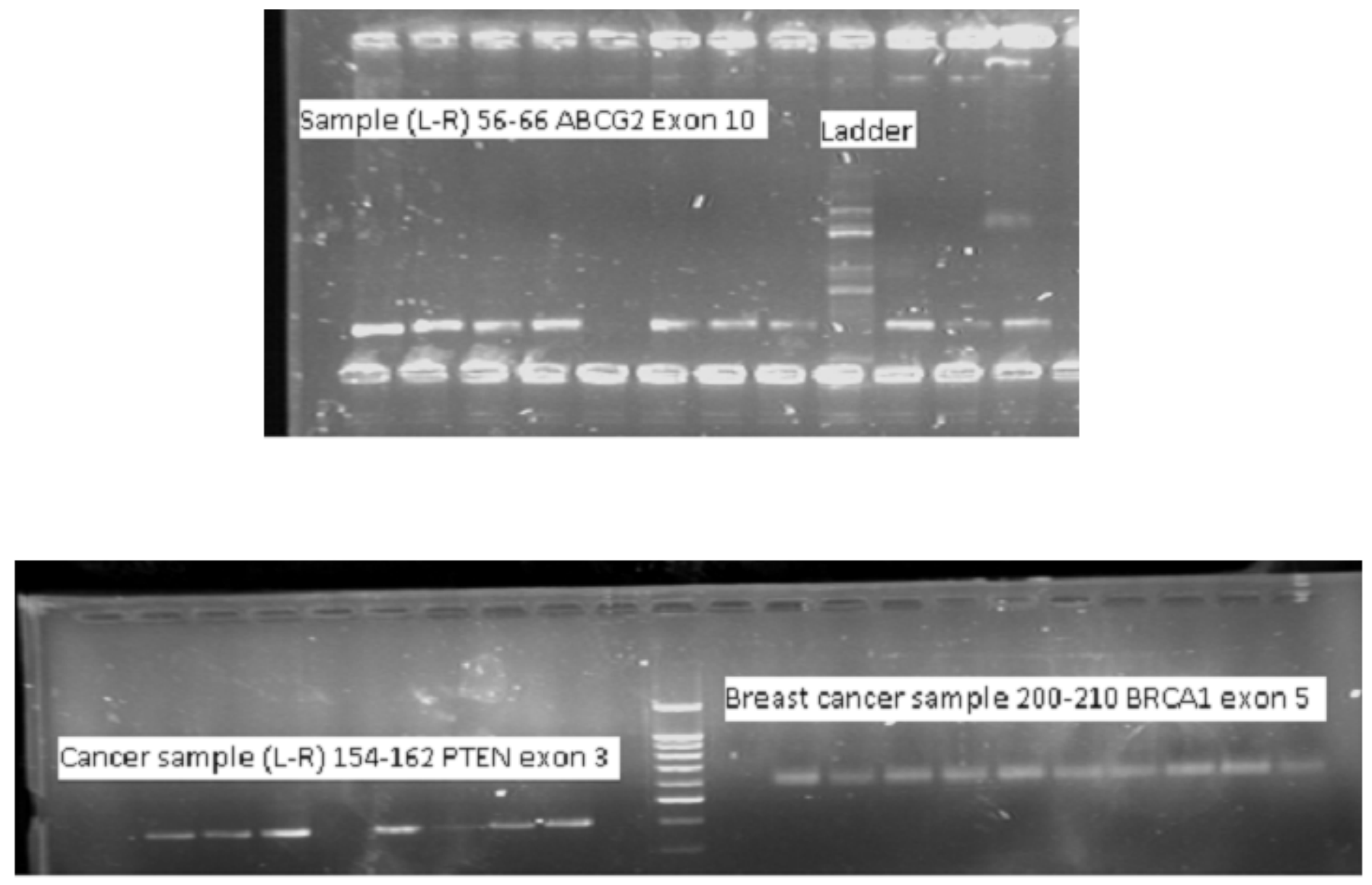

Figure 1

Few selected representative pictures of PCR product of ABCG2 gene exon 10, PTEN gene exon 3 BRCA1 gene exon 5

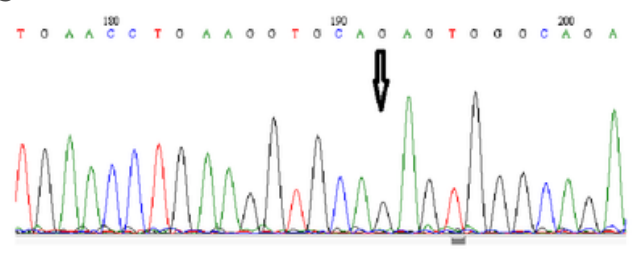

A

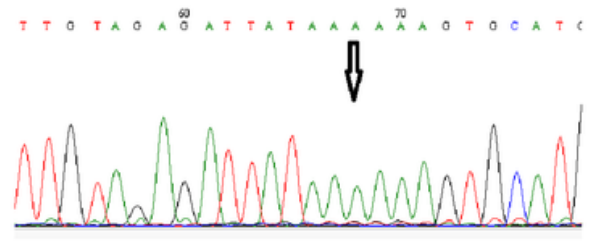

B

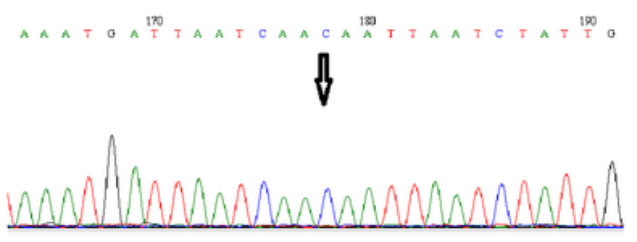

c

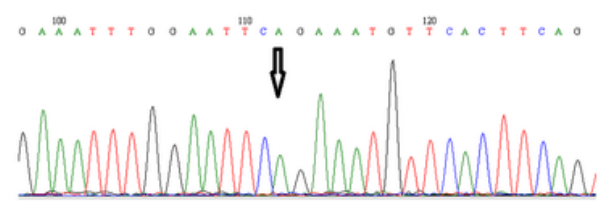

D

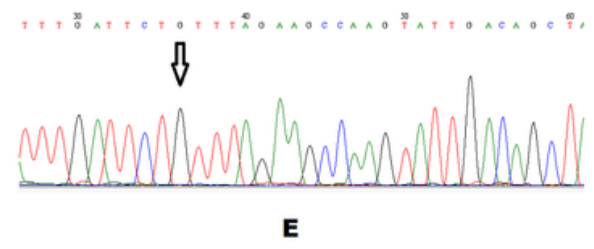

\section{Figure 2}

Sequenced electropherogram of ABCG2 gene A) exon 10, the arrow indicates the addition of $G$ in the sequence resulting in frameshift mutation $B$ ) mdr1 gene exon 14 the arrow indicates the substitution 
mutation in the sequence resulting in replacement of $G$ with A C) PTEN gene exon 8 the arrow indicates the substitution mutation in the sequence resulting in $\mathrm{G}$ to $\mathrm{C}$ mutation $\mathrm{D}$ ) BRCA1 gene exon 13 the arrow indicates the addition of $A$ in the sequence resulting in frameshift mutation E) BRCA1 gene exon 20 the arrow indicates the substitution mutation replacing $\mathrm{T}$ with $\mathrm{G}$.

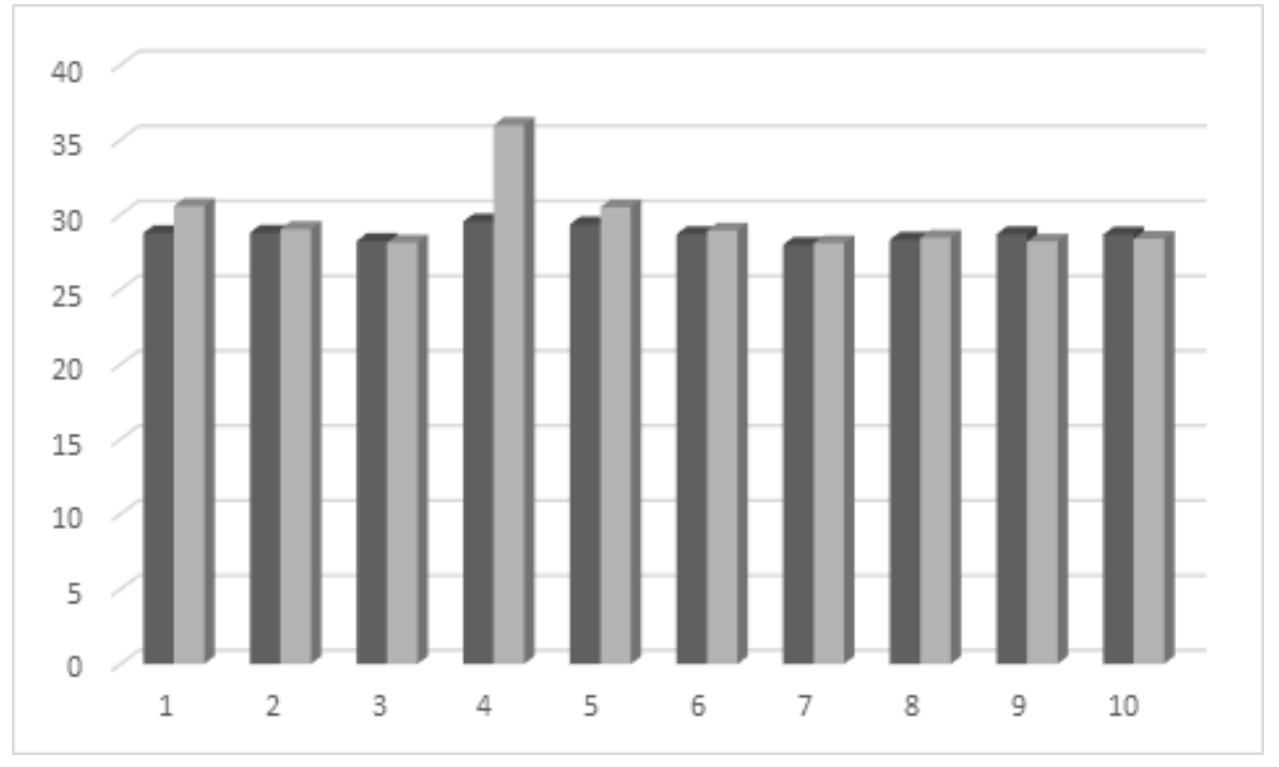

\section{Figure 3}

Graphical representation of tissue samples for miRNA-21 expressional variations analysis using realtime PCR. X-axis shows tissue sample number and $\mathrm{Y}$-axis shows copy number. Dark gray shows control tissue and light gray shows tumor tissue.

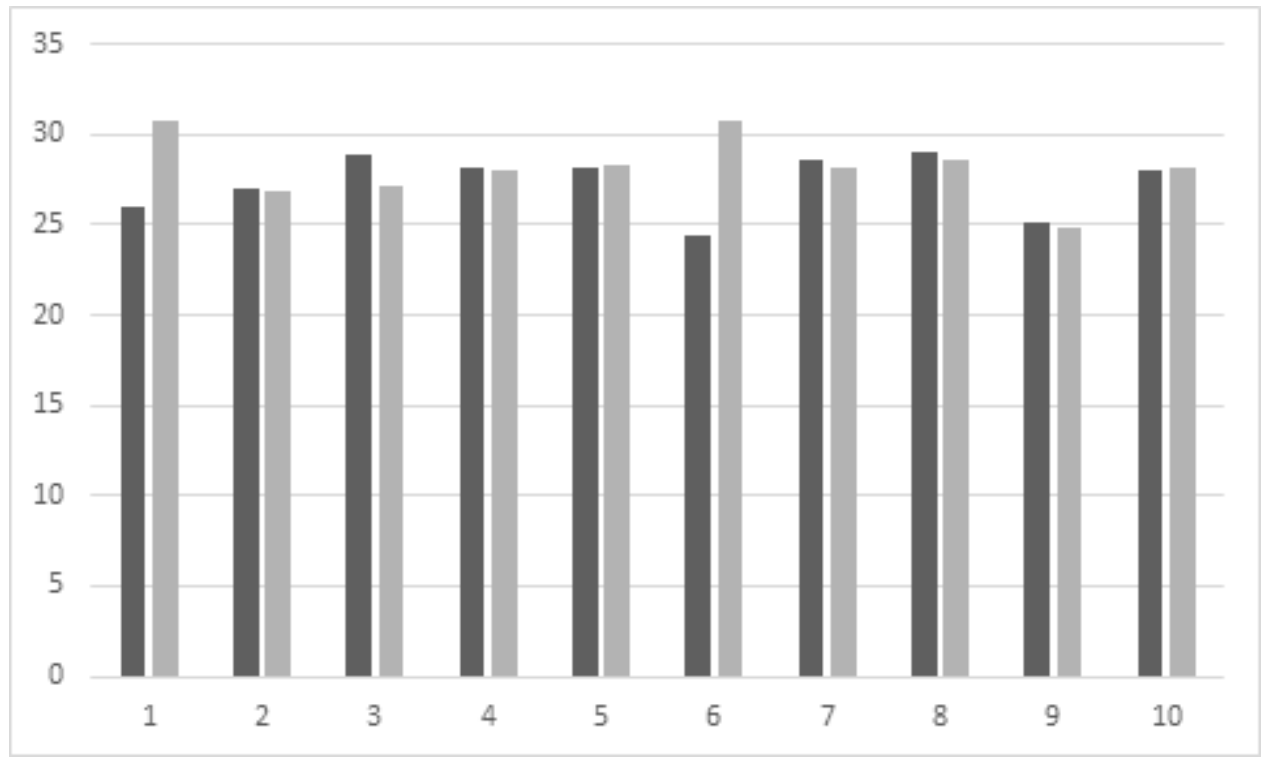

\section{Figure 4}

Graphical representation of tissue samples for miRNA-146a expressional variations analysis using realtime PCR. X-axis shows tissue sample number and $Y$-axis shows copy number. Dark gray shows control tissue and light gray shows tumor tissue. 


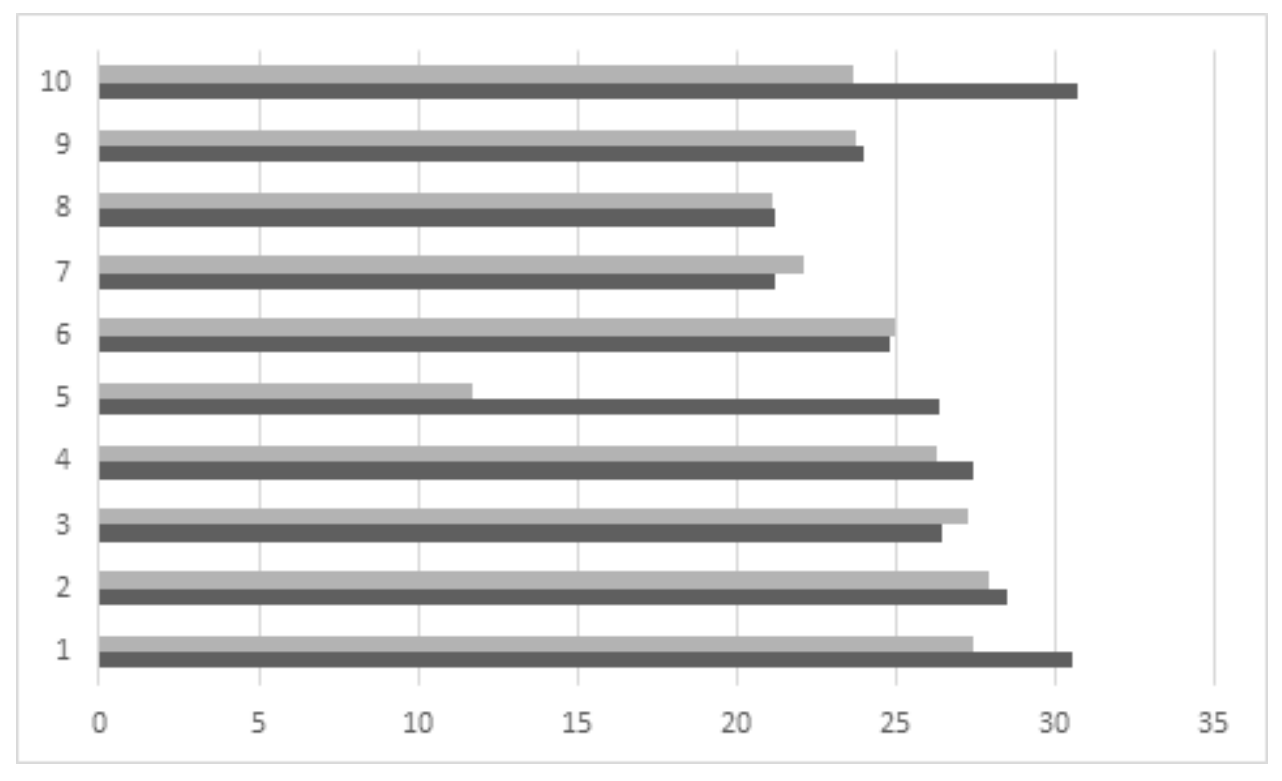

\section{Figure 5}

Graphical representation of tissue samples for miRNA-328 expressional variations analysis using realtime PCR. X-axis shows tissue sample number and $\mathrm{Y}$-axis shows copy number. Dark gray shows control tissue and light gray shows tumor tissue.

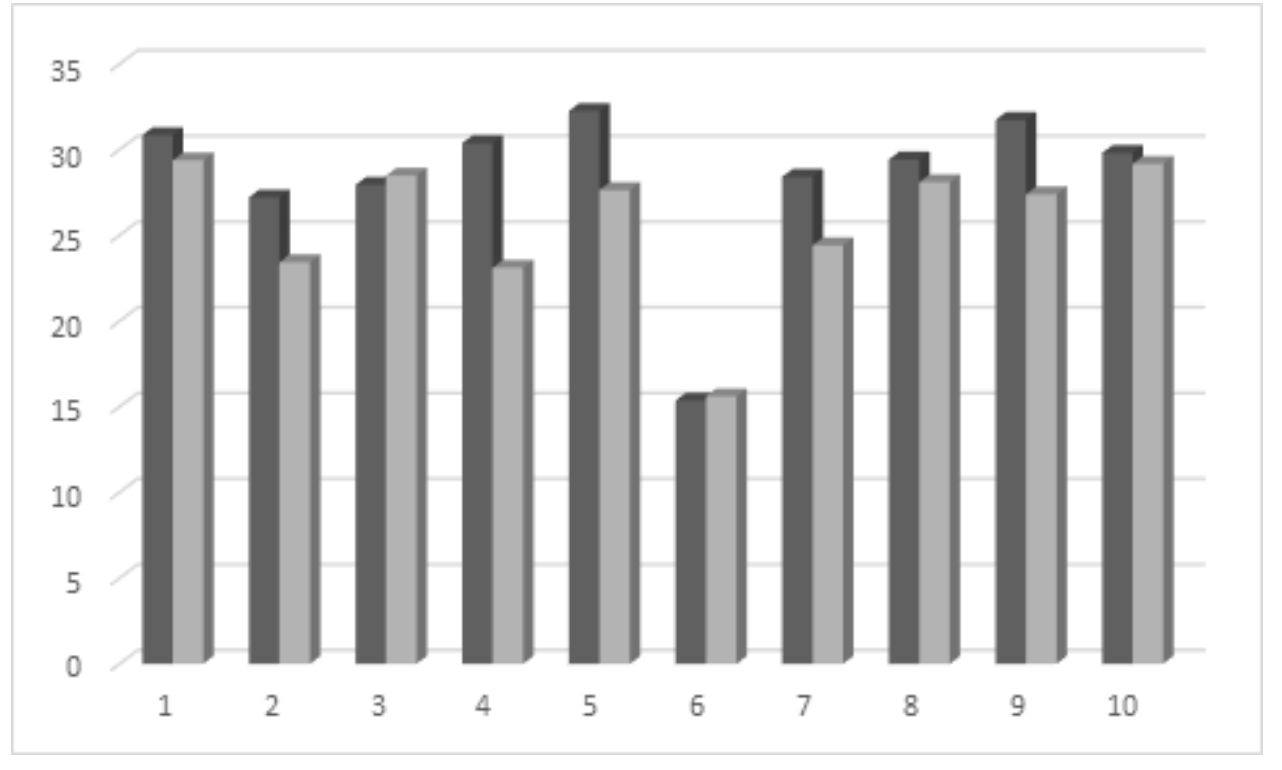

Figure 6

Graphical representation of tissue samples for miRNA-451 expressional variations analysis using realtime PCR. X-axis shows tissue sample number and $\mathrm{Y}$-axis shows copy number. Dark gray shows control tissue and light gray shows tumor tissue. 


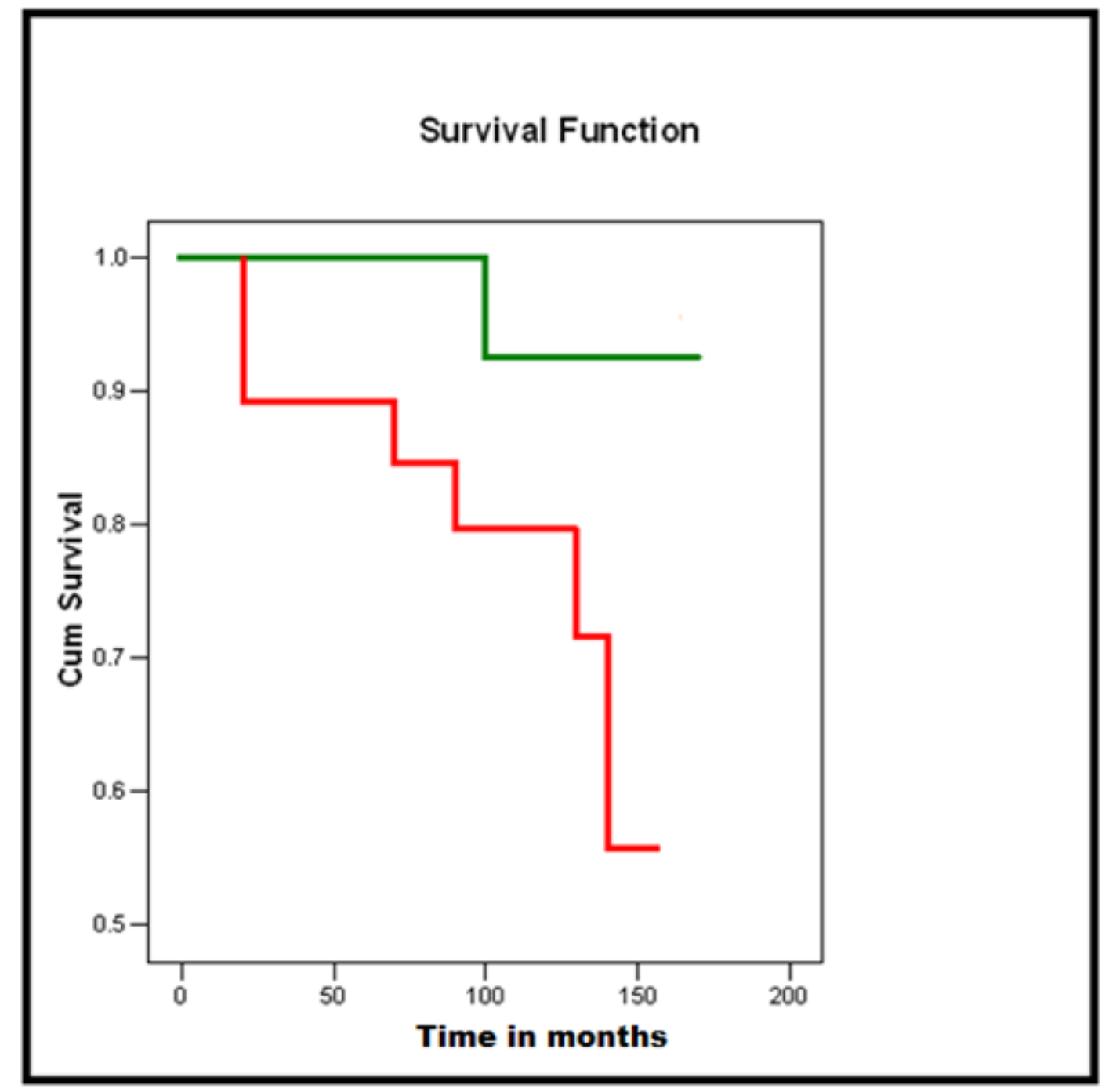

Figure 7

Kaplan Meier Survival analysis plotted against time for breast cancer patients. Red line showed higher variations and green lines showed less variations in genes and miRNAs showing greater survival probability. 